\title{
ON THE INTESTINE OF AMIA CALVA.
}

\author{
WILLIAM A. HILTON.
}

Although much work has been done upon the morphology and embryology of Amia, but little attention has been given to the microscopic anatomy of the intestine. After an examination of sections of Amia's intestine, and after comparing them with what has been done on the subject, it was found that there were many interesting but rather difficult problems which remained to be solved. In consideration of some of these points a more careful investigation was undertaken. ${ }^{1}$

In order to obtain a clear idea of the form of the mucosal convolutions, specimens were examined which had been injected with and preserved in either formalin or alcohol. For injecting the capillaries the "Berlin. blue injection mass" was used. The body was transsected caudad of the vent, and the injection made into the dorsal aorta within the hæmal arch. In making preparations to show cellular structures the usual histological fixers and stains were used; such fixers as Flemming's, Hermann's, Zenker's fluids and mercuric chloride solution; such stains as safranin, iron-hæmatoxylin and chloral hæmatoxylin, with picro-fuchsin.

The gross structure of Amia's intestine has been carefully described elsewhere (Hopkins, '92), so a simple description is all that is necessary to give here. The stomach lies parallel to the cephalic part of the intestine and joins it at a very acute angle; the pyloric valve marks the junction of the two parts and appears on the exterior as a very deep constriction. Internally, the pyloric valve projects as a tube a short distance into the cavity. The first part of the intestine is quite long and extends in a parallel line for about two-thirds the length of

1 The work was done in the histological laboratory of Cornell University. I wish especially to thank Professors Wilder, Gage, and Kingsbury for their valuable suggestions relating to the investigation. 
the abdominal cavity. After the first turn the intestine is of considerably less diameter than that of the first part. This second part, after quite an acute angle with the first part, ascends parallel with it for from one-third to one-half of its length, and then, after a very sharp turn, descends once more. After a few centimeters of descent the intestine bủlges out to a large diameter, indicating the location of the spiral valve; as it approaches the vent, the spiral valve having ended, the intestine once more becomes of small diameter. The spiral valve, which occupies a few centimeters of extent above the end of the rectum, has from four to four and one-half turns (Hopkins, '95).

Before taking up the finer structure of the intestine, the general form and arrangement of the mucosal convolutions will be considered. In this part of the study it was found that the character of the convolutions was much more easily and accurately made out from gross preparations than from sections, for, although serial sections may show much, a clear comprehension of all the complications can be obtained only by examination of the whole ental surface of the intestine. The following description is largely taken from a single specimen, one having been selected in which the most characteristic condition was presented. Upon a superficial examination of the intestine, slightly distended, the whole ental surface appears to be covered with villi thickly and irregularly placed, varying somewhat in height, but less in general shape, at different parts of the intestine. These appearances are to some extent deceptive; the upper part of the intestine is covered with a network of long and short zigzag folds and isolated villi. The folds run in every direction, and their free edges are more or less irregularly but deeply notched or wavy. Some of the projections or villi are perfectly isolated; others, which at first sight seem to be perfectly free, are found on more careful examination to have connection with their neighbors at the bases. There are all gradations, from perfectly isolated villi to irregular, short, zigzag folds. Many folds or nearly perfect villi join each other throughout their whole height; others slightly at their bases. All are of irregular, undulating heights. Many folds are several centimeters in extent, so that a very complicated 
appearance is presented. Between and about the network with the few isolated villi, which altogether form a rather loose meshwork, are much lower and much smaller villi or folds. These are not easily seen, because of the overshadowing higher folds and villi, and, in some specimens, seem to be altogether absent. Some of these lower, smaller folds are joined to the higher ones.

In one of the intestines examined there were, in one or two instances, clumps of folds in very close contact, almost cemented together in one mass; in other places the folds in little groups were in close contact when the intestine was not especially distended, but these, unlike the case just cited, could be separated from each other without tearing. In many cases folds are joined together in the form of a small ring or rather large crypt, not completely closed on one side; but in at least one case a complete ring or crypt was formed by the folds. There are comparatively few projections or villi which are completely separated from all about them, although in many cases the place where they unite with others may be of so little extent that it is easily overlooked.

The tendency of the folds, as well as the arrangement of the larger villi, seems to be fully as great toward a transverse as to a longitudinal direction. The higher villi begin at the pylorus with a height of about $.8 \mathrm{~mm}$., and at about the central portion or last portion of the first part of the intestine a height of about $3.5 \mathrm{~mm}$. to $3.8 \mathrm{~mm}$. may be reached; after this the folds and villi become gradually shorter caudad.

Nearer the pylorus folds can be more easily made out than a short distance below, because at first the folds are not so deeply indented on the free edges as farther down; they are also more numerous near the pylorus, that is, less split up into villi. With that part of the intestine a little above the first turn, the folds are more of them deeply split, and there are also numerous large villi, such as $3 \mathrm{~mm}$. long by $1.2 \mathrm{~mm}$. broad. The thickness of the folds and villi is about $.2 \mathrm{~mm}$., being in shape thin, plate-like, or leaf-like.

Below the first turn the folds are lower and appear a little more evenly placed, forming more of a continuous network of 
rather square meshes than was the case cephalad. Their free edges also seem to be less jagged, but, like those cephalad, they have wavy, free edges, and between the higher convolutions there are lower ones somewhat connected with the larger ones or free. There are comparatively few large, free projections or villi in this region.

At the beginning of the second turn the regular network appearance is usually lost, and the projections shorter, more irregular, and more jagged. After the most cephalic face of the spiral valve is passed, there are a few long, straight folds which appear to run in a longitudinal direction when the intestine is cut open lengthwise and slightly distended. Most of the other folds of the spiral valve might almost be considered to be villi, with rather broad bases and sharp tips. Below the spiral valve the convolutions are usually almost all longitudinally disposed; there are quite a number of low projections nearly free from each other, having rounded edges and arranged in parallel lines, almost like villi, but usually joined to each other by their bases.

The above description applies especially to medium-sized or rather large specimens, many points being obscure in smaller individuals, partly because of the smaller size of the convolutions, and partly because of individual variations. Aside from the usual variations which occur in all specimens without any special rule, there is a way in which large specimens differ from small in quite a constant manner; that is, the difference in the height of the convolutions, the larger individuals usually having longer projections than the smaller. This difference is rather a general one with the villi of many mammals and birds.

The muscular coats of the intestine are, as in all vertebrates, an outer longitudinal and an inner circular. The longitudinal coat is rather thin and made up of small, more or less irregular, bundles of plain muscle. The circular layer of muscle is enormously developed and, for most of its extent, seems to be of about the same thickness. There is but scant connective tissue about the bundles which make up the inner coat, while the connective tissue about the smaller bundles of the longitudinal coat is well developed. These muscular coats vary but little 
until the most caudal portion of the intestine is reached, and then, gradually, the muscle of the outer coat becomes less prominent, and at the end of the intestine the outside coat is made up of simply a thick band of connective tissue, with a very few small muscle bundles. There are so few of these that it does not seem that they have a very great part to play in the contraction of the intestine. The inner muscular coat undergoes no such decrease in size at the end of the intestine, but it does undergo some change, and at the last of the intestinal canal there is quite a marked decrease in the thickness of the coat, and the muscle fibres are not completely circularly arranged, as in the rest of the intestine; but a rather complex arrangement of the muscle fibres has taken place, which differs much from the perfectly circular layer of fibres in the other places (Fig. 8). Perhaps this complicated arrangement is partly to compensate for the diminished longitudinal coat and also to take on some new functions, such as some of the muscles of the rectum perform in higher animals.

Just entad of the inner muscular coat is a thick layer of connective tissue composed of fibres longitudinally disposed. This band of connective tissue is about as thick as, or somewhat thicker than, the outside muscular coat and very dense. It does not seem to vary throughout the intestine, except at the end, where it gives place to a dense mass of connective tissue and isolated clumps of plain muscle bundles. At this place the mass of muscle and connective tissue extends uniformly from: the epithelium to the inner muscular coat. It is about as thick as the two muscular coats together. With this exception the band of connective tissue is uniform throughout the intestine. It might be considered as an outside layer of submucosa, a sort of base upon which all the rest of the submucosa and mucosa rest. A dense connective-tissue band lying directly inside the muscular coats, but not so close to them as in Amia, has been described for several forms, as in the trout and Tinca oulgaris; this membrane has been called the membrana compacta or stratum compactum. Doubtless the connective-tissue layer in Amia is homologous to this membrana compacta.

Especially above the spiral valve connective-tissue strands 
from the membrana compacta extend to the tips of the folds and villi.

In the upper intestine the submucosa is rather thin, and but a scant muscularis mucosa exists. In the region of the spiral valve the submucosa above the stratum compactum is a little thicker, and a prominent muscularis mucosa is present, lying in a rather dense mass. There are in many places rather isolated muscle fibres of the muscularis mucosa going up into the villi, and the connective-tissue prolongations so characteristic of the upper intestine are not nearly so marked. The muscle fibres of the villi extend upwards longitudinally, and were, without doubt, derived from the muscularis mucosa, as in mammals and bircls. At the very end of the intestine, where folds and villi usually cease, there is an abundant muscularis mucosa, there being many longitudinal, and possibly a few transverse, muscle fibres and bundles of fibres scattered irregularly through all the dense connective tissue between the epithelium and muscular coats.

In general, the cores of the villi and folds, also all the submucosa above the stratum compactum, are composed of rather dense adenoid connective tissue. There are no lymphatic glands or patches of adenoid tissue anywhere in the intestine, but there are in many places areas of diffuse adenoid tissue, especially in the lower part of the intestine.

Before leaving the submucous structures to go on with those of the epithelium, it may be well to speak of the elements composing the spiral valve. Macallum ('86) states that in the spiral axis of Acipenser and Amia there is a large quantity of unstriated muscular fibres, which in Amia is aggregated into a single bundle. In Acipenser he states that there are several bundles arranged irregularly in direction and position, so it is almost impossible to conceive that they represent excessively developed portions of the muscularis mucosa. In Amia, although sections at times seem to show nearly a uniform bundle of muscle fibres occupying the central part of the valve, other and most of the sections show clearly numerous more or less closely placed bundles of plain muscle, most of the fibres running transversely, that is, nearly parallel with the free edges 
of the valve. Comparatively few run in the other direction. The muscularis mucosa at the base of the spiral valve is not especially thickened or diminished; it occupies its usual position on the ental side of the stratum compactum. The connective-tissue layer of the stratum compactum on each side of a turn of the spiral is seen in section to send upward into the spiral valve a thick portion of connective tissue; on the ental surface of each of these portions is the usual muscularis mucosa. These two layers meet in the basal part of the valve to form a sort of arch. Beneath the arch thus formed are muscle fibres composing one large bundle or several small bundles. It may be seen that in this way muscle and connective tissue are considerably mixed up in the basal part of the valve; but farther entad all become arranged once more, the muscle occupyingthe center of the valve, while on each side of it, between it and the submucosa, is a rather dense band of connective tissue; these bands, however, are not so dense as to prevent muscle fibres from going up into the villi (Fig. 9).

Three conclusions are to be drawn from the above complicated condition. First, the relative position of muscle and connective tissue is somewhat different from that in the intestine in general. Secondly, the core and, in fact, a large part of the spiral valve are made up of muscular tissue. Thircly, there is more muscle in the spiral valve than the double thickness of the muscularis mucosa, and although a small part of the muscle is derived from the muscularis mucosa, by far the larger part is not.

The intestinal epithelium of Amia presents a very interesting condition. The cells are exceedingly small, and in most places it is impossible to make out in sections the cell outlines. Macallum ('86) describes the epithelium to be composed of short cylinder cells resting on four layers of nuclei. This is often the appearance presented in sections; sometimes there seem to be six or eight layers of nuclei, especially in the upper part of the intestine; possibly, at times, a few of these nuclei may be those of underlying cells. Macallum figures the nuclei in even layers; this is seldom the case, the nuclei seeming to be scattered irregularly through the epithelium. They are 
usually somewhat elliptical, but may be irregularly circular. Isolated preparations from the epithelium are of the utmost value in determining the character and relation of cells. For isolating, Ranvier's dissociator of one-third alcohol was found to be especially good. The isolated cells were of the same length as the thickness of the epithelium, as shown in sections, the cell bodies being usually thin or even thread-like, with nuclei at all levels, thus showing with the greatest clearness that, although somewhat modified, the cells form a simple columnar epithelium. There might have been a few interposed cells at the bases of the longer ones, but if so they were not recognized. Usually, beneath the striated border of the cells is a band which takes a darker stain than the rest of the cell body. This was especially true of the epithelium towards the pylorus.

Although essentially similar in all parts of the intestine, the epithelium is especially thicker in the cephalic portion, there being in this first region a more complicated arrangement of nuclei at different levels. From the spiral valve caudad it is somewhat simpler, that is, it is not so thick, and the outlines of the cells are much easier to trace, there being at most but four layers of nuclei. Compared with the height of the epithelium of the lower intestine, there is greater distance from the surface to where the nuclei are located than is the case in the upper intestine. Goblet cells occur throughout the intestine, being more numerous caudad. In depth the thecas of the goblet cells occupy but a small proportion of the thickness of the epithelium or of the lengths of the cells of which they are parts. This is especially true of the upper part of the intestine.

Macallum ('86) describes cilia throughout the intestine of Amia. Comparing Macallum's statements with sections, in many places cilia seemed to be present, but careful examination of fresh specimens did not bear out these observations. In these experiments, as a check, living cilia were obtained from the œsophagus. Hopkins ('93) describes cilia in a very small area just caudad of the spiral valve; this is the only place in the intestine of Amia where true cilia occur; what 
appear to be cilia in other parts are simply the striated border of the epithelium. This border is best marked above the spiral valve; it becomes narrower as the caudad end of the intestine is reached.

The blood of the folds and villi in Amia is supplied by a capillary network which resembles the blood supply of the villi in higher forms. Large blood vessels run in the submucosa and send up branches into the folds and villi. With a villus there are usually three main trunks of arterioles going up into a fine capillary network. When the projections join each other, there are numerous small blood vessels which connect, to a greater or less extent, the two almost distinct capillary systems. The blood supply of the more distinct folds is practically the same as that of the villi-a continuous network, usually supplied by about as many main trunks as if a number of villi occupied the same position.

It will be seen from some of the preceding structures described that a very interesting condition exists in the form and structure of the enteric convolutions. The intestine of Amia presents an appearance midway between folds and villi, having some of both structures, the latter, in a way, developed from the former by unequal growth. The villi possess all the characteristic structures of villi of mammals and birds, as clo the folds, but falling short of villi simply because of their extent or lack of separation. In some of the higher forms, to a limited extent, signs of a transition from folds to villi are found, as in the double projections which occur occasionally in the small intestines of rabbits.

Villi have been clescribed in a few species of Pices, but their presence is not usual in this class. However, it may be noted that in general the forms in which villi have been described are what are generally regarded as the higher teleosts. As villi are characteristic of the highest vertebrates, such as mammals and birds, it is not difficult to accommodate villi to the highest fishes. But how are we to account for the specialized condition of the intestine of Amia? Simply as follows: Amia is a very ancient form of vertebrate, one that has changed but little from the ancestral type, and, therefore, has had as a 
species a long time for specialization, so the intestine has, during at least part of this time, become highly specialized, probably to suit more exactly the character of its food.

Another interesting point about Amia is the fact that in the spiral valve there is more muscular tissue than could have been derived from the muscularis mucosa. How did it get there? The answer to this question can be solved definitely only from the standpoint of embryology, but perhaps a suggestion may not be out of place. If the spiral valve was originally, if not in Amia in its progenitors, formed by a twisting of the whole thickness of the intestine, then a folding of the whole wall would, of course, involve the muscular coats as well as the submucosa and mucosa. In such a case muscle would be left in the spiral valve after readjustment of the outside coats once more to their usual appearance. Muscle from the muscularis mucosa would also be in the spiral valve, but the greater part would be from the muscular coats, and, because of the thickness of the inner muscular coat, the larger part of the muscle would run transversely, as is actually the case in the spiral valve of the adult.

\section{General Conclusions.}

I. The intestinal convolutions are very complex in form and arrangement, being made up of variously shaped folds and free projections or villi.

2. The muscular coats are well developed, an outer longitudinal and inner circular, the latter very thick.

3. A thick connective-tissue band, of uniform nature throughout the intestine, occurs next the inner muscular coat. This band of connective tissue sends up projections of fibres into some folds and villi.

4. A muscularis mucosa is present, a few fibres of which are prolonged into the cores of folds and villi.

5. The epithelium is simple, columnar, four to eight layers of nuclei appearing in sections.

6. The epithelium is not ciliated, except for a small area caudad of the spiral valve. 
7. The blood supply of the folds and villi is similar to that of the villi of mammals.

8. True villi and partially developed villi occur.

\section{CONDENSED BIBLIOGRAPHY.}

'66 Grimm, J. D. Ein Beitrag zur Anatomie des Darmes. Inaug.-Diss. Ser. 47. Taf. III. Dorpat.

'92 Hopkins, G. S. On the Digestive Tract of Some of the North American Ganoids. Abstract in Proc. Amer. Assoc. for the Ad $\%$. of Sci. Vol. xli, pp. 197, I98. Salem.

'93 Hopkins, G. S. Lymphatics and Enteric Epithelium of Amia calva. Wilder Quarter-Century Book. Pp. 367-384, 2 pls.

'95 Hopkins, G. S. On the Enteron of American Ganoids. Journ. of Morph. Vol. xi, pp. 367-384, 2 pls.

'86 Macallum, A. B. The Alimentary Canal and Pancreas of Acipenser, Amia, and Lepidosteus. Journ. Anat. und Phys. Bd. xx, pp. 604-636, Taf. I.

'29 Mrckel, J. F. System der vergleichenden Anatomie.

'81 Moreau, Émile. Histoire naturelle des poissons de la France. T. i, 220 figs. Paris.

'66-'68 Owen, R. Anatomy of Vertebrates. Vol. i. London.

'85 Pilliet, A. Sur la structure du tube digestif de quelques poissons de mer. Bull. Soc. Zool. France. Vol. x, pp. 283-308.

1800 Rudolphi, K. A. Einige Beobachtungen über die Darmzotten. Reils Arch. Ser. 4, p. 63. 


\section{EXPLANATION OF PLATE I.}

Fig. I. Intestine of medium-sized Amia calva; st., stomach; py.v., pyloric valve; $\mathrm{x}$, first turn of the intestine; 2 , second turn of the intestine; sp.v., region of the spiral valve; r., rectum.

FIG. 2. Folds and small villi of intestine near the pylorus ; $f$., fold ; v., villus.

FIG. 3. Intestine below first turn showing the ental surface; $f$., fold; $v$, villus.

Fig. 4. Last three faces of the spiral valve split lengthwise and distended, showing longitudinal folds on the spiral valve; f., fold; 2 , second face of valve; 3 , third face of valve; 4 , fourth face of valve; $w$., intestinal wall.

FIG. 5. Folds near the end of intestine. 

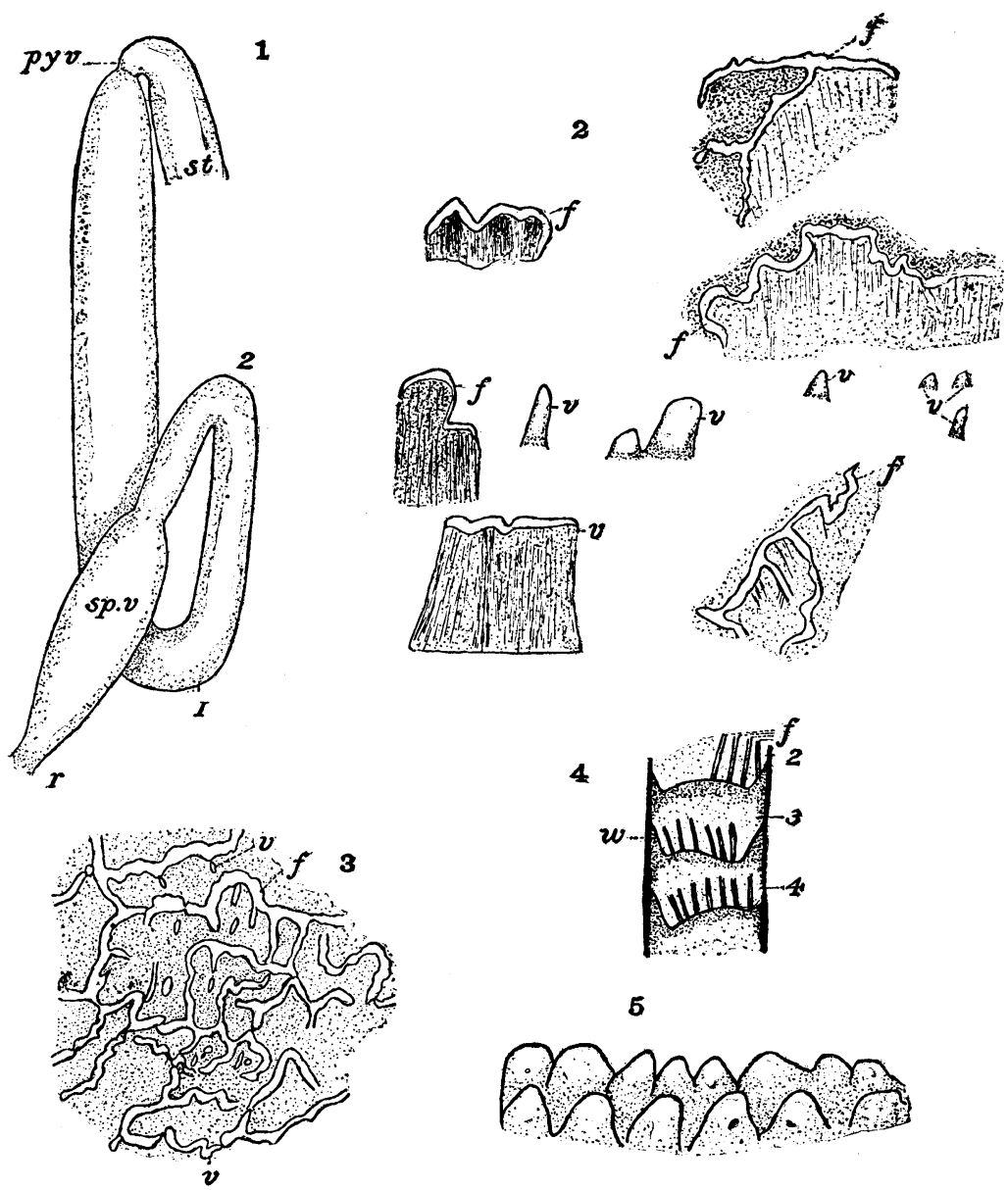

PLATE I.

This content downloaded from 142.109.001.196 on February 18, 2018 19:54:05 PM All use subject to University of Chicago Press Terms and Conditions (http://www.journals.uchicago.edu/t- 
$E$., epithelium ; $c$., cores of folds and villi ; ct., connective-tissue prolongations from the stratum compactum $(m$.$) ; im., inner muscular coat; om., outer muscular$ coat ; lm., lateral muscular bundles; tm., transverse muscular bundles ; $m b$., muscle bundles; mm., muscularis mucosa.

FIG. 6. Sections of the intestine near the pylorus, moderate magnification.

FIG. 7. Section of intestine below spiral valve.

FIG. 8. Section of the end of intestine.

FIG. 9. Transsection of spiral valve, not showing epithelium.

(All figures $\times 37$.) 

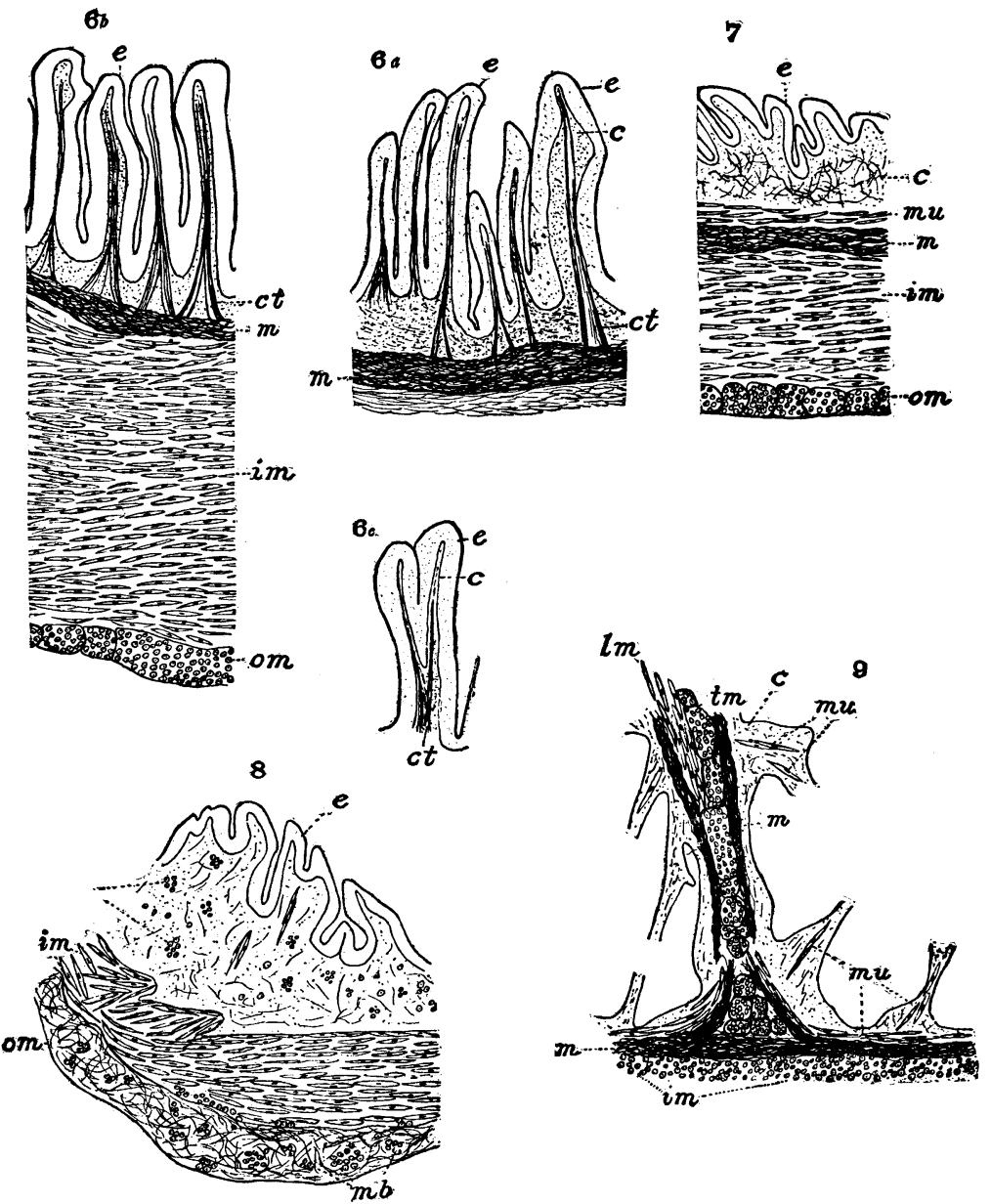

PLATE II.

This content downloaded from 142.109.001.196 on February 18, 2018 19:54:05 PM All use subject to University of Chicago Press Terms and Conditions (http://www.journals.uchicago.edu/t- 
Epithelium under $\mathrm{I} / \mathrm{I} 2$ in. oil immersion objective; $s$., striated border; $n$., nucleus ; $g$., goblet cell ; c., cell body.

FIG. Io (a), (b), (c). Sections of epithelium from the first part of the intestine.

FIG. II. Section of epithelium from the spiral valve.

FIG. I2. Section of epithelium near caudal end of the intestine.

FIG. I3. Isolated epithelial cells showing nuclei at all levels.

(All figures $\times 35^{\circ}$ ). 

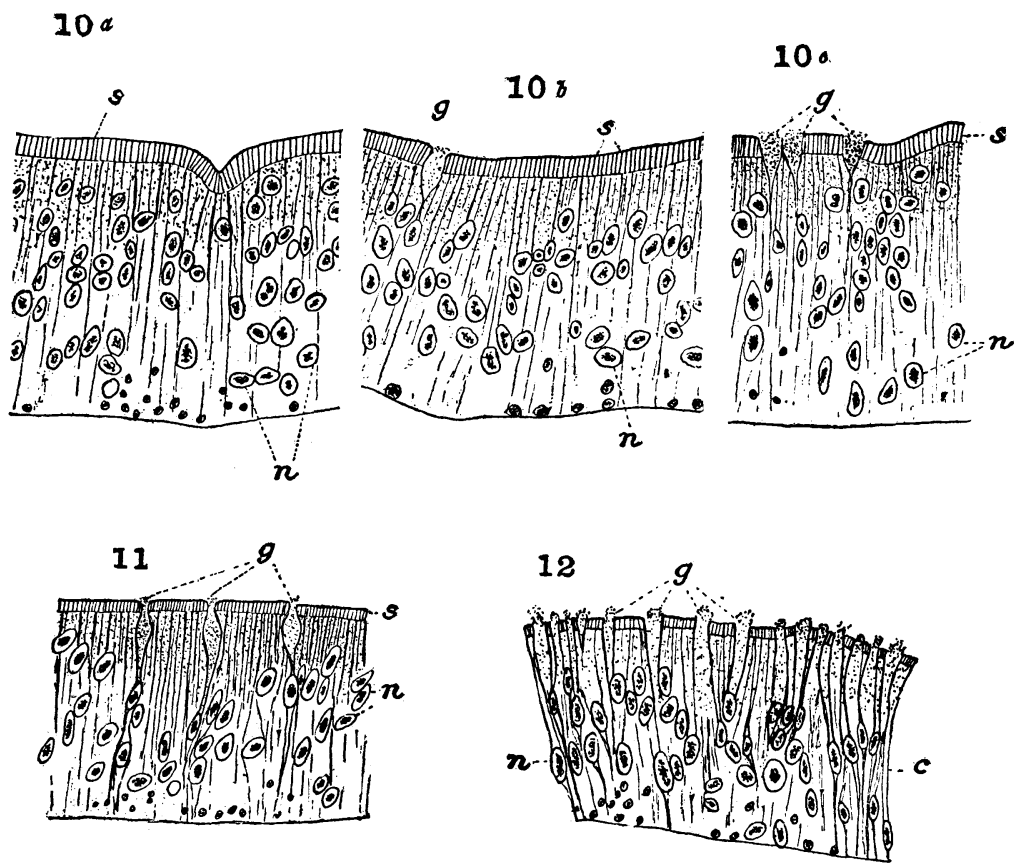

13
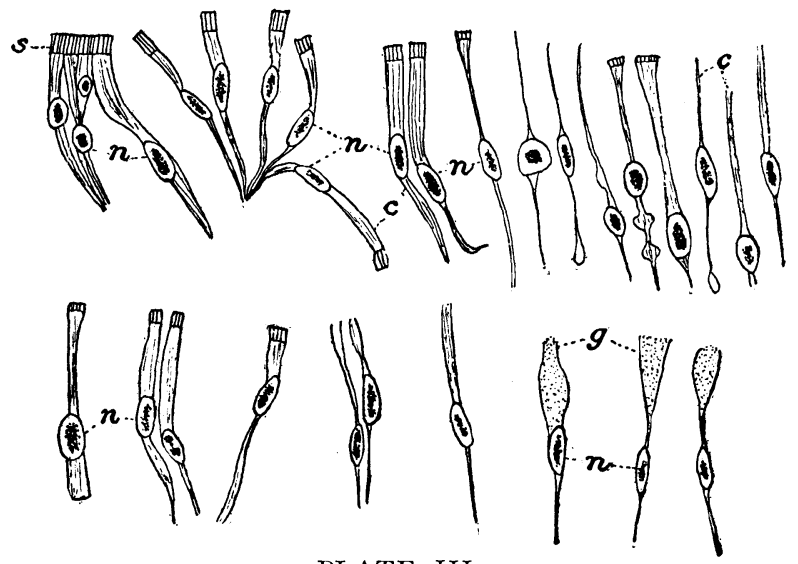

PLATE III. 
EXPLANATION OF PLATE IV.

Injected folds and villi, cores of villi alone represented, except in Fig. I9.

Frg. I4. Villus near the pylorus. $\times 70$.

FIG. I 5. Villi below the spiral valve. $\times 70$.

Fig. 16. Villus or part of fold on the spiral valve. $\times 70$.

Fig. I7. Villus or part of fold below the pylorus. $\times 70$.

Figs. 18, 19. Folds from near the pylorus less highly magnified than the above, showing the usual main arterioles with the network of capillaries, and also that the network in these cases is continuous. $\times 39$. 
14
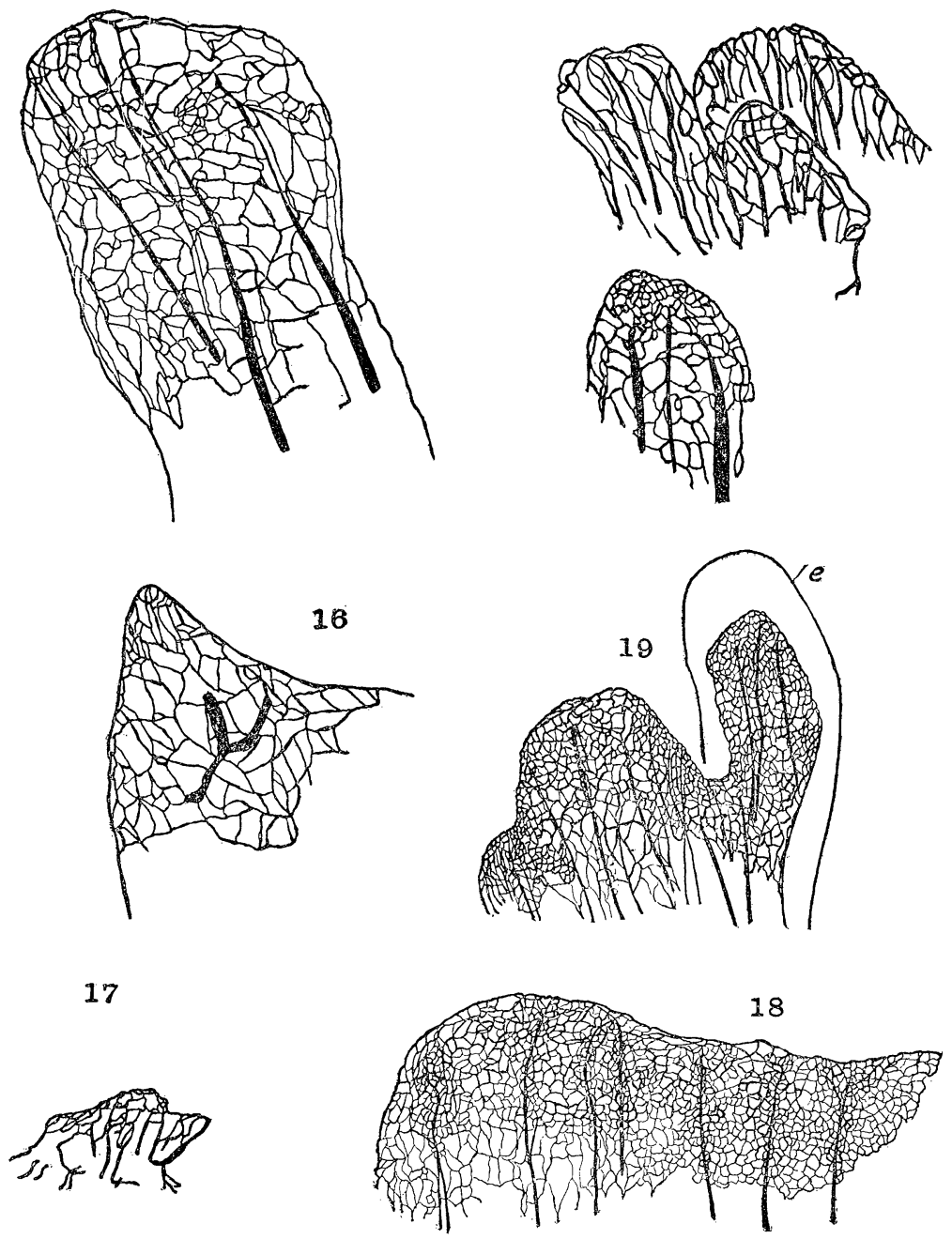

PLATE IV.

This content downloaded from 142.109.001.196 on February 18, 2018 19:54:05 PM All use subject to University of Chicago Press Terms and Conditions (http://www.journals.uchicago.edu/t- 